\title{
Molecular detection and characterization of Anaplasma spp. in sheep and cattle from Xinjiang, northwest China
}

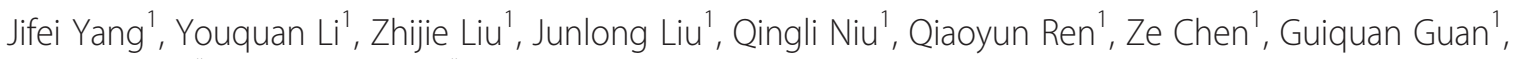
Jianxun Luo ${ }^{1 *}$ and Hong Yin ${ }^{1,2^{*}}$

\begin{abstract}
Background: Anaplasmosis is caused by obligate intracellular bacteria in the genus Anaplasma. These bacterial pathogens are transmitted by ticks and impact both human and animal health. This study was conducted to determine the prevalence and molecular characterization of Anaplasma spp. in ruminants sampled in Xinjiang, northwest China.

Methods: A survey was performed in August 2012 in rural areas of six counties in Xinjiang province. A total of 250 blood samples from ruminants were collected and tested for the presence of Anaplasma spp. by PCR. Positive samples were genetically characterized based on the $16 \mathrm{~S}$ rRNA and msp4 genes.

Results: The results showed a high prevalence of Anaplasma spp. in ruminants, with at least three different Anaplasma species detected (A. phagocytophilum, A. bovis and A. ovis). The mean prevalence of single infection with each species was 17.6\% (A. phagocytophilum), 4.8\% (A. bovis) and 40.5\% (A. ovis). Coinfection occurred in 20 (8.0\%) animals. Phylogenetic analysis of the $16 \mathrm{~S}$ rRNA gene of A. bovis and A. phagocytophilum revealed a higher degree of genetic diversity for the latter. The results for $A$. ovis showed genotypic variation among geographic regions in China. In addition, a closely related isolate to the canine pathogen A. platys was identified in ruminants.

Conclusions: This survey revealed a high prevalence of Anaplasma sp. infections in sheep and cattle in the northwestern border regions of China, indicating the potential risk of transboundary disease.
\end{abstract}

Keywords: $16 \mathrm{~S}$ rRNA gene, msp4 gene, Tick-borne disease

\section{Background}

The genus Anaplasma encompasses a group of obligate intracellular bacteria that infect a variety of cell types. These pathogens are transmitted by ticks and cause anaplasmosis in a number of animal species and humans [1]. Currently recognized species include A. phagocytophilum (previously recognized as Ehrlichia equi, E. phagocytophila, and the human granulocytic ehrlichiosis agent), A. marginale, A. ovis, A. bovis (formerly E. bovis) and A. platys (formerly E. platys). A. phagocytophilum infects neutrophils of human and animals and causes

\footnotetext{
*Correspondence: luojianxun@caas.cn; yinhong@caas.cn

'State Key Laboratory of Veterinary Etiological Biology, Key Laboratory of Veterinary Parasitology of Gansu Province, Lanzhou Veterinary Research Institute, Chinese Academy of Agricultural Science, Xujiaping 1, Lanzhou, Gansu 730046, P. R. China

Full list of author information is available at the end of the article
}

human, canine, and equine granulocytic anaplasmosis and tick fever in ruminants [1]. A. marginale, and A. ovis infect erythrocytes of domesticated and wild ruminants, while $A$. bovis causes disease in ruminants and small mammals using monocytes as their niche [2-4]. A. platys infects platelets and causes infectious cyclic thrombocytopenia in canines [5].

Several species of Anaplasma have been detected in Chinese ruminants, including A. phagocytophilum, A. bovis, A. marginale and A. ovis. A. phagocytophilum is thought to be maintained naturally in small mammaltick cycles, with Ixodes ticks as vectors [1,6]. This pathogen has been previously found in sheep, goats, cattle, rabbits, rodents and ticks in several provinces of China [7-10]. A. bovis has been most commonly reported in cattle and buffalo from Africa, the Middle East and 
South America [11]. More recently, molecular evidence for the presence of $A$. bovis was reported in both goats and cattle in China [12,13]. In addition, despite little information on the occurrence of $A$. marginale and $A$. ovis, these agents are known to cause severe disease in northern China [14,15].

Xinjiang is a large, sparsely populated province in northwest China that is bordered by India, Mongolia, Russia, Kazakhstan, Kyrgyzstan, Tajikistan, Afghanistan, and Pakistan that relies heavily on sheep farming for protein. A serological survey of A. phagocytophilum infections has been conducted in ruminants in Xinjiang [10]. Aside from the aforementioned study, information on the prevalence of Anaplasma species represents a gap in knowledge. Furthermore, information is scarce on the molecular characterization of $A$. phagocytophilum and other Anaplasma spp. in northwest China. In the present study, we show that domestic ruminants from the northwestern border regions of China are commonly infected by distinct Anaplasma species. We also present molecular evidence for a potentially novel Anaplasma sp. closely related to A. platys in cattle. Our results will be useful for the risk assessment of the cross-border spread of anaplasmosis.

\section{Methods}

\section{Study sites and collection of specimens}

The survey was performed in August 2012 in rural areas of Kashgar, Akto, Artux, Yecheng, Pishan and Hotan counties in Xinjiang province. Sampling sites were located in the south and west of Xinjiang province, near the border with Kyrgyzstan, Tajikistan, Afghanistan and Pakistan. For each county, two to three sites were selected for sampling. Blood samples were taken from the jugular vein of 250 asymptomatic domestic ruminants (sheep and cattle, $\mathrm{n}=125 /$ each species) and collected in a sterile tube containing an anticoagulant (EDTA). DNA was extracted from $300 \mu \mathrm{L}$ of blood using the Gentra Puregene DNA purification kit (Qiagen, Beijing, China) according to the manufacturer's instructions.

\section{$\mathrm{PCR}$ reactions}

The extracted DNA was examined by nested PCR for the presence of $A$. phagocytophilum and A. bovis $16 \mathrm{~S}$ rRNA gene and $A$. ovis major surface protein 4 (msp4) gene as previously described $[16,17]$. The reaction was performed in an automatic thermocycler (Bio-Rad) with a total volume of $25 \mu \mathrm{L}$ containing $2.5 \mu \mathrm{L}$ of $10 \times$ PCR buffer $\left(\mathrm{Mg}^{2+}\right.$ Plus), $2.0 \mu \mathrm{L}$ of each dNTP at $2.5 \mathrm{mM}$, $1.25 \mathrm{U}$ of Taq DNA polymerase (TaKaRa), $2.0 \mu \mathrm{L}$ of template DNA, $1.0 \mu \mathrm{L}$ of each primer $(10 \mathrm{pmol})$, and 16.25 $\mu \mathrm{L}$ of distilled water. Genomic DNA extracted from infected animals was used as the positive control, and sterile water was used as the negative control.
Cycling conditions for 16S rRNA amplification were: $4 \mathrm{~min}$ of denaturation at $94^{\circ} \mathrm{C}, 35$ cycles at $94^{\circ} \mathrm{C}$ for $1 \mathrm{~min}$, annealing for $1 \mathrm{~min}$ at $55^{\circ} \mathrm{C}$, and $72^{\circ} \mathrm{C}$ for $1 \mathrm{~min}$, with a final extension step at $72^{\circ} \mathrm{C}$ for $10 \mathrm{~min}$. For $\mathrm{msp} 4$ amplification, after an initial denaturation step of $30 \mathrm{~s}$ at $94^{\circ} \mathrm{C}$, each cycle consisted of a denaturing step of $30 \mathrm{~s}$ at $94^{\circ} \mathrm{C}$, an annealing for $30 \mathrm{~s}$ at $60^{\circ} \mathrm{C}$, and an extension step of $1 \mathrm{~min}$ at $68^{\circ} \mathrm{C}$. PCR products were visualized by UV transillumination in a $1.0 \%$ agarose gel following electrophoresis and staining with ethidium bromide.

\section{DNA sequencing and phylogenetic analysis}

Positive PCR products were purified using the TaKaRa Agarose Gel DNA purification Kit Ver.2.0 (TaKaRa, China), ligated into pGEM-T Easy vector (Promega, USA) and transformed into Escherichia coli JM109 competent cells (TaKaRa, China). Two recombinant clones were selected for sequencing using BigDye Terminator Mix (Sangon, China). The obtained sequences were analyzed by a BLASTn search in GenBank or by using the Clustal W method in the MegAlign software (DNAStar, Madison, WI). A phylogenetic tree was then constructed based on the sequence distance method using the neighbor-joining (NJ) algorithm with the Kimura twoparameter model of the Mega 4.0 Software [18].

\section{Statistical analysis}

The results were analyzed using a Chi-square test in Predictive for Analytics Software (PASW) Statistics 18. A difference was considered statistically significant at $P<0.05$.

\section{Nucleotide sequence accession numbers}

The GenBank accession numbers for the 16S rRNA gene sequences obtained in this study were as follows: KJ782381-KJ782387 for A. phagocytophilum detected in sheep, KJ782388-KJ782392 for A. phagocythopilum detected in cattle, and KJ782393-KJ782395 for A. bovis detected in cattle. The msp4 gene sequences of $A$. ovis were assigned accession numbers KJ782396-KJ782404.

\section{Ethical approval}

This study was approved by the Animal Ethics Committee of Lanzhou Veterinary Research Institute, Chinese Academy of Agricultural Sciences. Animals were handled in accordance with the Animal Ethics Procedures and Guidelines of the P. R. China.

\section{Results}

Out of 250 sampled animals, 44 (17.6\%) were positive for A. phagocytophilum (Table 1). The average positive rates were $40.5 \%$ and $28.8 \%$ for A. ovis and A. phagocytophilum in sheep $(\mathrm{n}=125)$, respectively. Eighteen $(14.4 \%)$ samples were simultaneously positive to $A$. ovis and $A$. 
Table 1 Detection of Anaplasma pathogens in sheep and cattle at various geographic sites

\begin{tabular}{|c|c|c|c|c|c|c|c|c|c|}
\hline \multirow[t]{3}{*}{ County } & \multicolumn{9}{|c|}{ No. infected/(\%) } \\
\hline & \multirow{2}{*}{$\begin{array}{l}\text { No. } \\
\text { tested }\end{array}$} & \multicolumn{3}{|l|}{ Sheep } & \multirow{2}{*}{$\begin{array}{l}\text { No. } \\
\text { tested }\end{array}$} & \multicolumn{3}{|l|}{ Cattle } & \multirow[t]{2}{*}{ Total } \\
\hline & & A. ovis & A. phago* & A. ovis + A. phago & & A. bovis & A. phago & A. bovis + A. phago & \\
\hline Yecheng & 20 & $18(90.0)$ & $5(25.0)$ & $4(20.0)$ & 22 & $1(5.0)$ & $0(0)$ & $0(0)$ & 42 \\
\hline Akto & 23 & $0(0)$ & $0(0)$ & $0(0)$ & 22 & $1(4.3)$ & $4(17.4)$ & $0(0)$ & 45 \\
\hline Pishan & 20 & $10(50.0)$ & $1(5.0)$ & $1(5.0)$ & 21 & $1(5.0)$ & $1(5.0)$ & $1(5.0)$ & 41 \\
\hline Hotan & 20 & $5(25.0)$ & $0(0)$ & $0(0)$ & 20 & $0(0)$ & $0(0)$ & $0(0)$ & 40 \\
\hline Kashgar & 19 & $14(73.7)$ & $9(47.4)$ & $9(47.4)$ & 20 & $2(10.5)$ & $3(15.8)$ & $1(5.3)$ & 39 \\
\hline Artux & 23 & $4(17.4)$ & $21(91.3)$ & $4(17.4)$ & 20 & $1(4.3)$ & $0(0)$ & $0(0)$ & 43 \\
\hline Total & 125 & $51(40.5)$ & $36(28.8)$ & $18(14.4)$ & 125 & $6(4.8)$ & $8(6.4)$ & $2(1.6)$ & 250 \\
\hline
\end{tabular}

*A. phago $=$ A. phagocytophilum

phagocytophilum. For cattle $(\mathrm{n}=125)$, the average positive rates were $4.8 \%$ and $6.4 \%$ for $A$. bovis and $A$. phagocytophilum, respectively. Coinfection occurred in only two (1.6\%) of the sampled cattle. As shown in Table 1, three-pathogens were found in four of six study sites. In other sites, $A$. ovis was the only pathogens detected in Hotan, while A.bovis and A. phagocytophilum were found in Akto.

To characterize these agents detected in sheep and cattle, positive samples representative of different hosts and geographic locations were sequenced, 25 sequences were obtained in this study. The partial $16 \mathrm{~S}$ rRNA gene (642 and $551 \mathrm{bp)}$ of A. phagocytophilum and A. bovis as well as msp4 (869 bp) of A. ovis were analyzed. After BLAST and CLUSTAL W alignment, 12 PCR products of A. phagocytophilum chosen as representative of different hosts and geographic locations resulted in four different $16 \mathrm{~S}$ rRNA gene sequence types. The different types of $16 \mathrm{~S}$ rRNA sequences identified for A. phagocytophilum in this study are designated as $1-4$. The similarity among sequence types 1-4 ranged from $97.2 \%$ to 99.5\%, showcasing the genetic diversity of $A$. phagocytophilum in China. Types 1 and 2 (PS6, KS6, KS20, AKT11 and AKT4) were found to be $98.8 \%$ and $99.2 \%$ identical to strain CE18 (GenBank accession no. GQ450278) that was detected in the Cervus elaphus from Poland [19]. Type 3 (ATS1 and ATS15) had 98.3\% identity to the HB231 strain (GenBank accession no. JN558816) derived from goat in Hubei, China [13]. Type 4 (YC38, YC29, PS19, KS9 and KS8) was 98.6\% identical to strain ES34 (GenBank accession no. AB196720) that was detected in deer from Japan [16].

The 16S rRNA $A$. bovis sequences identified in cattle were 99.8 to $100 \%$ identical, despite geographic separation. Two isolates (YC7 and AKT5) were 100\% identical to strain ES1019 (GenBank accession no. HQ913644), which was found in a Chinese goat. One isolate (KS2) was $99.8 \%$ identical to a strain found in Chinese cattle (GenBank accession no. FJ169957, strain name was not available). In addition, one isolate (KS6) showed high similarity (98.5\%) to strains of A. platys (GenBank accession no. JQ894779 and AF156784). Sequence analysis of msp4 amplicons confirmed their identity to A. ovis. Nine msp4 sequences (ATS12, ATS20, HT29, HT32, KS7, KS9, PS3, YC25 and YC26) were $99.5 \%$ to $100 \%$ identical to each other and showed $99.8 \%$ to $100 \%$ identity to $A$. ovis genotype AOI identified in sheep from Italy (GenBank accession no. EU436160) [20].

Phylogenetic analyses indicated that the $16 \mathrm{~S}$ rRNA sequence types from $A$. phagocytophilum formed three main clusters, implying geographic and host segregation of strains in China (Figure 1). Cluster one displayed a close relationship with the sequence amplified from deer found in Poland (GenBank accession no. GQ450278). Cluster two showed a close relationship with the sequence amplified from a goat in central China (GenBank accession no. KF569916 and JN558816). Cluster three clustered independently from all known $A$. phagocytophilum sequences. Three isolates of $A$. bovis were classified into a cluster together with isolates from Chinese goat and cattle (GenBank accession no. HQ913644 and FJ169957) as well as South Korean deer (GenBank accession no. AB682764) (Figure 2). No geographic segregation of $A$. bovis isolates was observed in this study. One sequences derived from cattle showed a close relationship with $A$. platys and grouped in a separate clade with isolate Gzh981 from a Chinese dog (GenBank accession no. AF156784) (Figure 2), indicating that cattle are an alternative host of $A$. platys in China. Nine isolates of $A$. ovis were closely related to $A$. ovis genotype AOI reported in Italy (GenBank accession no. EU436160) and separated from isolates reported in China (GenBank accession no. HQ456347-HQ456350) (Figure 3).

\section{Discussion}

In this study, we performed a molecular survey of Anaplasma pathogens of human and veterinary interest in northwest China. Our findings revealed that not only are 


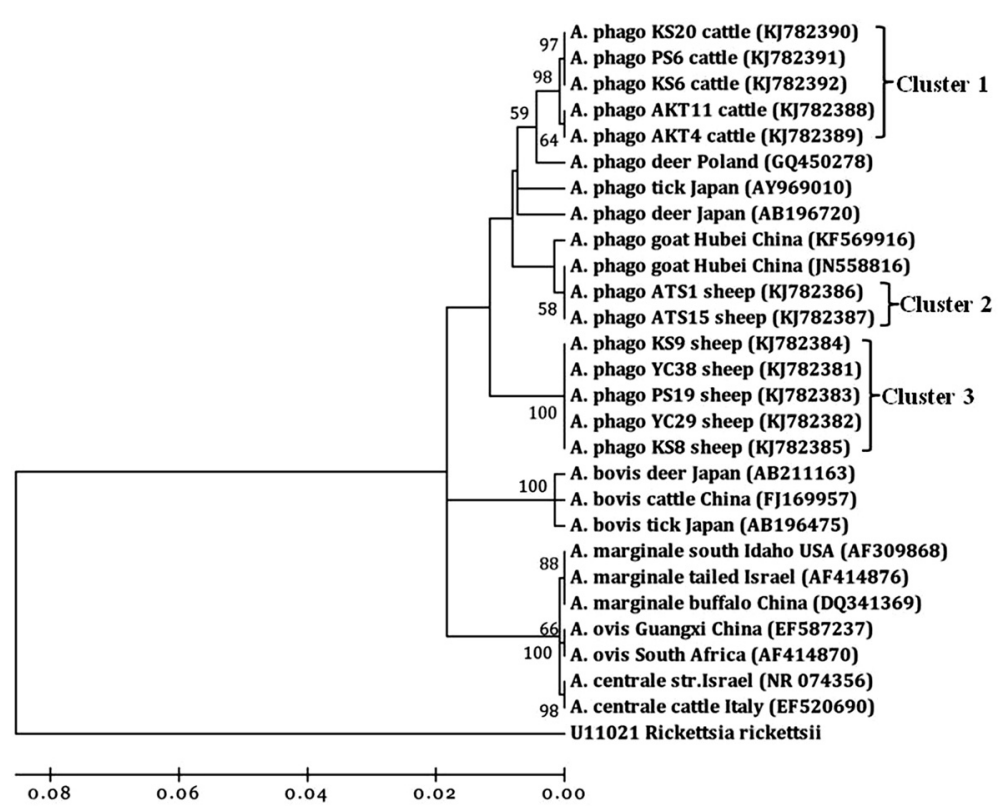

Figure 1 Phylogenetic analysis of $A$. phagocytophilum (A. phago) based on $16 \mathrm{~S}$ rRNA gene partial sequences. A neighbor joining tree was constructed using the Kimura two-parameter model in Mega 4.0. An alignment of 16S rRNA sequences from position 694 to 1334 of the sequence (based on strain ES34, GenBank accession no. AB196720) was used to construct this tree. Rickettsia rickettsii is used as an outgroup.

A. phagocytophilum, A. bovis and A. ovis present in animals from different study sites, but an $A$. platys-like pathogen was also present.

A. phagocytophilum is known as an emerging human pathogen of public health relevance [21]. In addition to humans, many domestic animals, such as dogs, cats, horses, sheep, goats, and cattle, can become infected with $A$. phagocytophilum and show clinical signs with high fever, depression, anorexia and weight loss [22]. Previous reports revealed that the infection rates for $A$. phagocytophilum were variable in different hosts and geographic locations in China. Several molecular surveys have shown that $A$. phagocytophilum infection rates of: 5.7\% (8/35), 13.0\% (6/46), 14.5\% (10/69), 38.5\% (35/91)

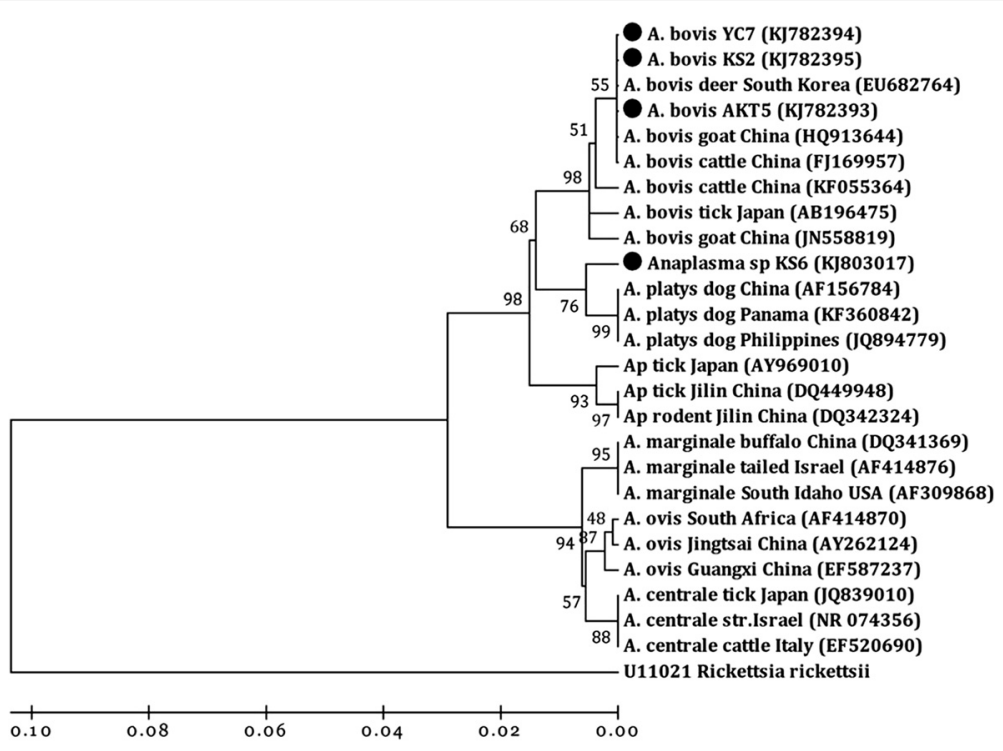

Figure 2 Phylogenetic analysis of $A$. bovis based on $16 \mathrm{~S}$ rRNA gene partial sequences. A neighbor joining tree was constructed using the Kimura two-parameter model in Mega 4.0. An alignment of 16S rRNA sequences from position 60 to 610 of the sequence (based on strain ES1019, GenBank accession no. HQ913644) was used to construct this tree. Rickettsia rickettsii is used as an outgroup. $\bullet$ : sequences in this study. 


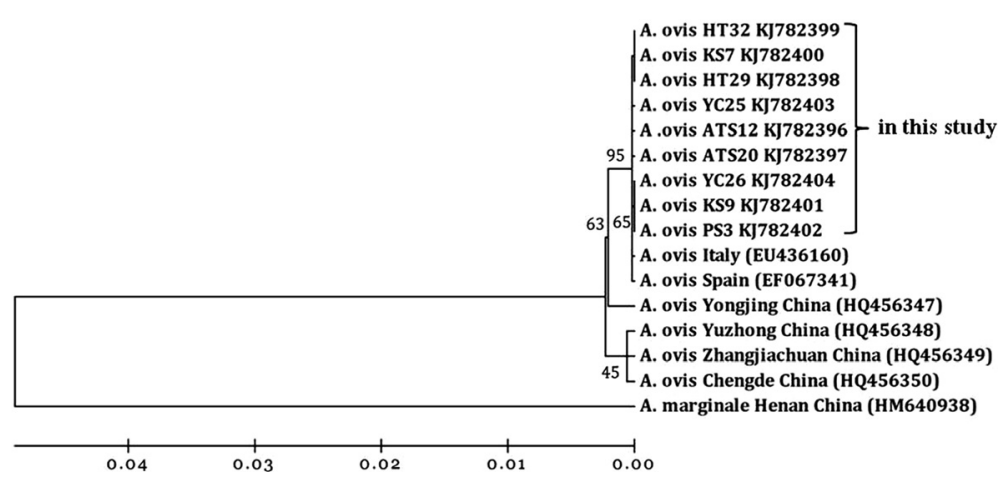

Figure 3 Phylogenetic analysis of $A$. ovis strains based on the deduced amino acid sequences for the $m s p 4$ gene. A neighbor joining tree was constructed using the Kimura two-parameter model in Mega 4.0. An alignment of full length Msp4 sequences was used to construct this tree.

in goats from Jilin, Henan, Hubei and Gansu; 7.1\% (5/ $70)$ and $42.9 \%(21 / 49)$ in sheep from Jilin and Gansu; $6.8 \%(38 / 557)$ in rodents from Heilongjiang, Jilin and Zhejiang; and $3.42 \%(83 / 2429)$ in ticks from different sites near the China-Russia border $[8,13,23,24]$. In the present study, the average positive rates of $A$. phagocytophilum were $28.8 \%$ and $6.4 \%$ in sheep and cattle, respectively. The positive rate was significantly higher in sheep than in cattle $(P<0.001)$. However, it is hard to conclude that sheep were a more suitable host for $A$. phagocytophilum in our study sites as the difference in infection rates could be explained by the known tick vectors that transmit $A$. phagocytophilum. A. phagocytophilum is usually associated with ticks of the genus Ixodes [25,26]. However, because of its capacity for transstadial and transovarial transmission, Dermacentor albipictus may be another vector for A. phagocytophilum [27]. Moreover, A. phagocytophilum DNA has been detected in $H$. concinna, $H$. longicornis, $H$. qinghaiensis, I. persulcatus and Dermacentor silvarum in China $[23,24,26]$, indicating that numerous tick species may maintain or be involved in the transmission of A. phagocytophilum. As a number of tick species are considered to be host specific [28], we assume that the sheep were infested with tick vectors that preferentially feed on sheep as compared to cattle, and that this resulted in a higher prevalence of $A$. phagocytophilum in sheep. These results indicated that both sheep and cattle are part of the natural maintenance cycle of A. phagocytophilum. A. phagocytophilum appears to exhibit ecotypes with different host ranges and zoonotic potential [29], It is unclear at this stage how the Chinese genotypes would segregate into ecotypes, however, in a European study genotypes that infected cattle were in the same ecotype as those that infected humans [29]. Clearly, the finding of cattle infected with $A$. phagocytophilum warrants further investigation.

The $A$. phagocytophilum 16S rRNA gene sequences identified herein were analyzed together with sequences reported previously for the characterization of the genetic diversity of $A$. phagocytophilum strains in comparison with other Anaplasma spp. Four different $16 \mathrm{~S}$ rRNA genotypes of $A$. phagocytophilum were identified in this study, indicating that A. phagocytophilum is genetically diverse within China. Similar results have been reported in goats from central and southern China [13]. Phylogenetic analyses revealed these genotypes formed three main clusters. Interestingly, the genotypes 1 and 2 (99.5\% similarity) derived from cattle were classified into one cluster and separated from type 3 and 4 derived from sheep. This result suggested that $A$. phagocytophilum genotypes may vary between sheep and cattle. Several studies reported that $A$. phagocytophilum strains differ in host infectivity [29-31]. In this study, cluster 1 (genotypes 1 and 2) were more likely to infect cattle; while cluster 2 (genotype 3 ) and 3 (genotype 4) were more likely to infect sheep. In addition, cluster 3 was in a divergent cluster from the other $A$. phagocytophilum sequences, implying that it is genetically distinct from the known $A$. phagocytophilum strains described in China (Figure 1).

A. bovis has a wide host range, encompassing both domestic and wild mammals. Susceptible species include cattle, goats, dogs, cats and deer $[11,13,16,32,33]$. Investigation of $A$. bovis infections in cattle showed a prevalence that ranged between 0 and $10.5 \%$, with an average of $4.8 \%$, which was significantly lower than the prevalence in cattle $(53.3 \%)$ in Japan [11]. In recent years, molecular evidence for A. bovis infection in goats showed a higher prevalence of $49.6 \%$ in central and southern China [13], and in sheep and goats in southwestern China [12]. Considering this, we sought to determine whether the $A$. bovis was present in sheep at our study sites. Unfortunately, A. bovis DNA was not detected in sheep samples in this study. Sequences analysis revealed that $A$. bovis amplified from our sampled cattle were grouped into one cluster and had high identity with isolates from Chinese goat and cattle. According to our 
results, and in contrast to A. phagocytophilum, no host segregation or geographical isolation was observed among A. bovis strains in China. Surprisingly, despite the capacity of $A$. bovis to infect multiple hosts and its wide distribution, $A$. bovis $16 \mathrm{~S}$ rRNA gene sequences were less genetically diverse compared with $A$. phagocytophilum (Figure 2).

$A$. platys shows unique tropism for dog platelets, being the etiological agent of the infectious canine cyclic thrombocytopenia [4]. Interestingly, an $A$. platys-like pathogen was found in cattle from Kashgar county in this study. This isolate (KS6, KJ803017) was closely related to A. platys and is a sister taxon to A. platys isolates in dogs from China, Panama and the Philippines (Figure 2). This is not the first report for A. platys-like pathogen detected in ruminants. In previous studies, $A$. platys-like organisms have been reported in goats from central and southern China [13], and in sheep, goats and cattle with a high prevalence $(55.6 \%, 55 / 99)$ from the Island of Sardinia, Italy [4]. These results suggest that ruminants are a likely alternative host for $A$. platys.

The average infection rate of $A$. ovis (40.5\%) in sheep was slightly lower than that in goats (with an average of $46.6 \%)$ from central and southern China $(P>0.05)$, indicating wide distribution and enzootic stability [13]. Phylogenetic analysis of $m s p 4$ sequences revealed one $A$. ovis $m s p 4$ genotype in sheep that was closely related to A. ovis genotype AOI from Italy (GenBank accession no. EU436160) [20]. A previous study identified six A. ovis msp4 genotypes in sheep and goats from China [13]. However, the isolates in Xinjiang were phylogenetically separated from all of them, indicating genotypic variation among geographic regions. Considering Anaplasma major surface proteins (MSPs) are likely to evolve more rapidly than other genes because they are subjected to selective pressures exerted by host immune systems [17], the variation of msp 4 sequences observed in sheep and goats was low (Figure 3).

Finally, coinfection occurred in $20(8.0 \%)$ of the sampled animals. The coinfection rate $(18 / 125,14.4 \%)$ of $A$. phagocytophilum and $A$. ovis in sheep was significantly higher than the coinfection rate $(2 / 125,1.6 \%)$ of $A$. phagocytophilum and $A$. bovis in cattle $(P<0.01)$. In addition, one sample from cattle (KS6) was simultaneously positive for $A$. phagocytophilum and an A. platys-like organism. Although Anaplasma species show different preferential host and cell tropism $[1,3,4]$, coinfection increases the potential difficulty in diagnosis of Anaplasma infection. Furthermore, investigation of potential tick vectors will be useful for understanding the life cycle and promoting a comprehensive strategy to both prevent and control these pathogens.

\section{Conclusions}

Infections with $A$. phagocytophilum, $A$. bovis and $A$. ovis bacteria are endemic in ruminants from northwest
China. Our survey revealed a high prevalence of Anaplasma sp. infections in sheep and cattle in the northwestern border regions of China, indicating a potential risk for transboundary disease.

\section{Competing interests}

The authors declare that they have no competing interests.

\section{Authors' contributions}

$\mathrm{HY}$ and $J \mathrm{~L}$ designed this study and critically revised the manuscript. JY participated in its design, coordination and manuscript revision. JY, YL, ZL and JL participated in sample collection. JY, QN, QR, GG and ZC performed the experiments, data analysis, and drafted the manuscript. All authors read and approved the final manuscript.

\section{Acknowledgements}

This study was financially supported by the Supporting Program (2013BAD12B03, 2013BAD12B05), ASTIP, CAAS; Creative Research Groups of Gansu Province (№1210RIA006); NBCIS CARS-38, Special Fund for Agro-scientific Research in the Public Research (№201303035), MOA; 973 Program (2010CB530206), Specific Fund for Sino-Europe Cooperation, MOST, China; State Key Laboratory of Veterinary Etiological Biology Project.

\section{Author details}

${ }^{1}$ State Key Laboratory of Veterinary Etiological Biology, Key Laboratory of Veterinary Parasitology of Gansu Province, Lanzhou Veterinary Research Institute, Chinese Academy of Agricultural Science, Xujiaping 1, Lanzhou, Gansu 730046, P. R. China. ${ }^{2} J i a n g s u$ Co-innovation Center for Prevention and Control of Important Animal Infectious Diseases and Zoonoses, Yangzhou 225009, P. R. China.

Received: 27 August 2014 Accepted: 9 February 2015

Published online: 19 February 2015

\section{References}

1. Dumler JS, Barbet AF, Bekker CP, Dasch GA, Palmer GH, Ray SC, et al. Reorganization of genera in the families Rickettsiaceae and Anaplasmataceae in the order Rickettsiales: unification of some species of Ehrlichia with Anaplasma, Cowdria with Ehrlichia and Ehrlichia with Neorickettsia, descriptions of six new species combinations and designation of Ehrlichia equi and 'HGE agent' as subjective synonyms of Ehrlichia phagocytophila. Int J Syst Evol Microbiol. 2001;51(Pt 6):2145-65.

2. Sreekumar C, Anandan R, Balasundaram S, Rajavelu G. Morphology and staining characteristics of Ehrlichia bovis. Comp Immunol Microbiol Infect Dis. 1996;19(1):79-83.

3. Rar V, Golovljova I. Anaplasma, Ehrlichia, and "Candidatus Neoehrlichia" bacteria: pathogenicity, biodiversity, and molecular genetic characteristics, a review. Infect Genet Evol. 2011;11(8):1842-61.

4. Zobba R, Anfossi AG, Pinna Parpaglia ML, Dore GM, Chessa B, Spezzigu A, et al. Molecular investigation and phylogeny of Anaplasma spp. in Mediterranean ruminants reveal the presence of neutrophil-tropic strains closely related to A. platys. Appl Environ Microbiol. 2014;80(1):271-80.

5. Harvey JW, Simpson CF, Gaskin JM. Cyclic thrombocytopenia induced by a Rickettsia-like agent in dogs. J Infect Dis. 1978;137(2):182-8.

6. Bown KJ, Begon M, Bennett M, Woldehiwet Z, Ogden NH. Seasonal dynamics of Anaplasma phagocytophila in a rodent-tick (Ixodes trianguliceps) system, United Kingdom. Emerg Infect Dis. 2003;9(1):63-70.

7. Zhan L, Cao WC, Jiang JF, Zhang XA, Liu YX, Wu XM, et al. Anaplasma phagocytophilum from rodents and sheep, China. Emerg Infect Dis. 2010;16(5):764.

8. Zhan L, Cao WC, Jiang JF, Zhang XA, Wu XM, Zhang WY, et al. Anaplasma phagocytophilum in livestock and small rodents. Vet Microbiol. 2010;144(3-4):405-8.

9. Zhan L, Chu CY, Zuo SQ, Wu XM, Dumler JS, Jia N, et al. Anaplasma phagocytophilum and Borrelia burgdorferi in rabbits from southeastern China. Vet Parasitol. 2009;162(3-4):354-6.

10. Chahan B, Jian Z, Xuan X, Sato Y, Kabeya H, Tuchiya K, et al. Serological evidence of infection of Anaplasma and Ehrlichia in domestic animals in Xinjiang Uygur Autonomous Region area, China. Vet Parasitol. 2005;134(3-4):273-8. 
11. Ooshiro M, Zakimi S, Matsukawa Y, Katagiri Y, Inokuma H. Detection of Anaplasma bovis and Anaplasma phagocytophilum from cattle on Yonaguni Island, Okinawa, Japan. Vet Parasitol. 2008;154(3-4):360-4.

12. Zhou Z, Nie K, Tang C, Wang Z, Zhou R, Hu S, et al. Phylogenetic analysis of the genus Anaplasma in Southwestern China based on 16S rRNA sequence. Res Vet Sci. 2010;89(2):262-5.

13. Liu Z, Ma M, Wang Z, Wang J, Peng Y, Li Y, et al. Molecular survey and genetic identification of Anaplasma species in goats from central and southern China. Appl Environ Microbiol. 2012;78(2):464-70.

14. Bai Q, Chen Z, Ying S, Liu G, Zhou J. Study on isolation and preservation of single species of haematocytozoon in bovine: separation of bovine $A$. marginale single isolate. Chin J Vet Sci Tech. 1987;3:12-5.

15. Ma L, Hua N, Chen W. Investigation of ovine anaplasmosis. J Xinjiang Anim Hus Sci Tech. 1982;2:2-13.

16. Kawahara M, Rikihisa Y, Lin Q, Isogai E, Tahara K, Itagaki A, et al. Novel genetic variants of Anaplasma phagocytophilum, Anaplasma bovis, Anaplasma centrale, and a novel Ehrlichia sp. in wild deer and ticks on two major islands in Japan. Appl Environ Microbiol. 2006;72(2):1102-9.

17. de la Fuente J, Atkinson MW, Naranjo V, Mera IG de F, Mangold AJ, Keating $\mathrm{KA}$, et al. Sequence analysis of the msp4 gene of Anaplasma ovis strains. Vet Microbiol. 2007:119(2-4):375-81.

18. Tamura K, Dudley J, Nei M, Kumar S. MEGA4: Molecular Evolutionary Genetics Analysis (MEGA) software version 4.0. Mol Biol Evol. 2007;24 (8):1596-9.

19. Hapunik J, Vichova B, Karbowiak G, Wita I, Bogdaszewski M, Pet'ko B. Wild and farm breeding cervids infections with Anaplasma phagocytophilum. Ann Agric Environ Med. 2011;18(1):73-7.

20. Torina A, Alongi A, Naranjo V, Estrada-Pena A, Vicente J, Scimeca S, et al. Prevalence and genotypes of Anaplasma species and habitat suitability for ticks in a Mediterranean ecosystem. Appl Environ Microbiol. 2008;74(24):7578-84.

21. Chen SM, Dumler JS, Bakken JS, Walker DH. Identification of a granulocytotropic Ehrlichia species as the etiologic agent of human disease. J Clin Microbiol. 1994;32(3):589-95.

22. Poitout FM, Shinozaki JK, Stockwell PJ, Holland CJ, Shukla SK. Genetic variants of Anaplasma phagocytophilum infecting dogs in Western Washington State. J Clin Microbiol. 2005:43(2):796-801.

23. Jiang JF, Jiang BG, Yu JH, Zhang WY, Gao HW, Zhan L, et al. Anaplasma phagocytophilum infection in ticks, China-Russia border. Emerg Infect Dis. 2011;17(5):932-4.

24. Yang J, Liu Z, Guan G, Liu Q, Li Y, Chen Z, et al. Prevalence of Anaplasma phagocytophilum in ruminants, rodents and ticks in Gansu, north-western China. J Med Microbiol. 2013;62(Pt 2):254-8.

25. Bown KJ, Lambin X, Telford GR, Ogden NH, Telfer S, Woldehiwet Z, et al. Relative importance of Ixodes ricinus and Ixodes trianguliceps as vectors for Anaplasma phagocytophilum and Babesia microti in field vole (Microtus agrestis) populations. Appl Environ Microbiol. 2008;74(23):7118-25.

26. Cao WC, Zhao QM, Zhang PH, Yang H, Wu XM, Wen BH, et al. Prevalence of Anaplasma phagocytophila and Borrelia burgdorferi in Ixodes persulcatus ticks from northeastern China. Am J Trop Med Hyg. 2003;68(5):547-50.

27. Baldridge GD, Scoles GA, Burkhardt NY, Schloeder B, Kurtti TJ, Munderloh UG. Transovarial transmission of Francisella-like endosymbionts and Anaplasma phagocytophilum variants in Dermacentor albipictus (Acari: (xodidae). J Med Entomol. 2009:46(3):625-32.

28. Wells K, O'Hara RB, Pfeiffer M, Lakim MB, Petney TN, Durden LA. Inferring host specificity and network formation through agent-based models: tick-mammal interactions in Borneo. Oecologia. 2013;172(2):307-16.

29. Jahfari S, Coipan EC, Fonville M, van Leeuwen AD, Hengeveld P, Heylen D, et al. Circulation of four Anaplasma phagocytophilum ecotypes in Europe. Parasit Vectors. 2014;7:365.

30. Foley JE, Nieto NC, Massung R, Barbet A, Madigan J, Brown RN. Distinct ecologically relevant strains of Anaplasma phagocytophilum. Emerg Infect Dis. 2009;15(5):842-3.

31. Massung RF, Mather TN, Levin ML. Reservoir competency of goats for the Ap-variant 1 strain of Anaplasma phagocytophilum. Infect Immun. 2006;74(2):1373-5
32. Sakamoto L, Ichikawa Y, Sakata Y, Matsumoto K, Inokuma H. Detection of Anaplasma bovis DNA in the peripheral blood of domestic dogs in Japan. Jpn J Infect Dis. 2010;63(5):349-52.

33. Tateno M, Nishio T, Sakuma M, Nakanishi N, Izawa M, Asari Y, et al. Molecular epidemiologic survey of Bartonella, Ehrlichia, and Anaplasma infections in Japanese Iriomote and Tsushima leopard cats. J Wildl Dis. 2013;49(3):646-52

\section{Submit your next manuscript to BioMed Central and take full advantage of:}

- Convenient online submission

- Thorough peer review

- No space constraints or color figure charges

- Immediate publication on acceptance

- Inclusion in PubMed, CAS, Scopus and Google Scholar

- Research which is freely available for redistribution 